\title{
Biorelevant Dissolution Method Development for Dutasteride and Tamsulosin Hydrochloride Modified Release Capsule Simulating Post-prandial Condition
}

\author{
Devi Thamizhanban ${ }^{1, *}$, Gampa Tulja Rani ${ }^{2}$, Kathiresan Krishnasamy ${ }^{1}$ \\ 'Department of Pharmacy, Annamalai University, Annamalai Nagar, Chidambaram, Tamil Nadu, INDIA \\ ${ }^{2}$ Malla Reddy Pharmacy College, Maisammaguda, Hyderabad, Telangana, INDIA.
}

\begin{abstract}
Objectives: This research work is aimed to develop bio relevant dissolution method by simulating human gastrointestinal condition at post-prandial state. The quality control dissolution procedure for modified release product using simple buffers of specific $\mathrm{pH}$ is not adequate for prediction of in vivo performance. Methods: Percentage of drug absorbed is derived by deconvolution of drug plasma concentration at post-prandial condition using Wagner-Nelson deconvolution method. Quality control dissolution test is performed using office of generic drugs recommended dissolution method. Bio relevant dissolution method is developed using USP Apparatus 3 (reciprocating cylinder), with quality by design approach. A full factorial design of experiment study is performed for optimization of dips per minute and media volume. Separate dissolution method is developed for tamsulosin and dutasteride, since the formulation design and release profile are different for both drugs. Results: The dissolution profile obtained using quality control procedure is observed faster in comparison to percentage of drug absorbed. The bio relevant dissolution method developed for tamsulosin part is, $250 \mathrm{ml}$ of Fed state simulated change over dissolution media with 15DPM, based on desirability factor 0.8767
\end{abstract}

and for dutasteride part is, $100 \mathrm{ml}$ of $\mathrm{pH} 6.5$ Fed state simulated intestinal fluid with 20DPM, based on desirability factor 0.5836, achieved from multiple response optimizations. The dissolution results are comparable to percentage of drug absorbed. The regression co-efficient $\left(R^{2}\right)$ value of 0.998 and 0.982 demonstrates a very good in vitro/in vivo correlation under post-prandial condition for tamsulosin and dutasteride respectively. Conclusion: The developed method shall be used as a predictive in vitro tool for evaluation of in vivo performance under post-prandial condition. Key words: Biorelevant, Dutasteride, Tamsulosin, Post-prandial, Deconvolution.

Correspondence

Mrs. Devi Thamizhanban

Research Scholar, Department of Pharmacy, Annamalai University, Annamalai Nagar, Tamil Nadu - 608002, INDIA

Phone no: +919840946681

Email: devrajmphd@gmail.com

DOI: 10.5330/ijpi.2020.3.63

\section{INTRODUCTION}

Dutasteride/Tamsulosin hydrochloride modified-release capsule is a hard gelatin capsule consists of an immediate-release soft gelatin capsule containing dutasteride $500 \mathrm{mcg}$ and modified-release multi particulates containing tamsulosin hydrochloride $400 \mathrm{mcg}$. The combination product is used for the treatment of moderate to severe symptomatic Benign Prostatic Hyperplasia (BPH) in men. ${ }^{1}$

Dutasteride is poorly soluble, absorbed rapidly after oral administration and observed with $60 \%$ bioavailability. $\mathrm{C}_{\max }$ is observed about $4-5 \mathrm{hrs}$, with the biological half-life $\left(\mathrm{t}_{1 / 2}\right)$ of 50-60hrs, when administered after food. ${ }^{2}$ Tamsulosin is absorbed completely after oral administration with $100 \%$ bioavailability. $\mathrm{C}_{\max }$ is observed about $11-12 \mathrm{hrs}$, with the biological half-life $\left(\mathrm{t}_{1 / 2}\right)$ of $12-13 \mathrm{hr}$, when administered after food. ${ }^{3}$

Plasma drug concentration is based on pharmacokinetic profile of drug product depends on absorption rate and elimination rate. Whereas, dissolution is based on cumulative percentage of drug released. WagnerNelson deconvolution method is used to identify the percentage of drug absorbed from drug plasma concentration time profile, with the aid of elimination rate and half-life of the specific product, using onecompartment model. ${ }^{4}$ For immediate release products, which are having longer biological half-life, the deconvolution is recommended to evaluate up to the $\mathrm{C}_{\max }$ of drug product, since, no drug release occurs after stipulated period of time. ${ }^{5}$
Dissolution is a critical quality attribute for solid oral dosage form. Pharmacopoeial or quality control dissolution procedures are mainly used to characterise the extent of dissolution for immediate-release formulation, rate and extent of drug release for modified-release formulation. If individual monograph is not available, USP recommends standard dissolution apparatus and limits based on type of dosage form. ${ }^{6}$ Generally, quality control test for dissolution is performed by using standard buffer, with or without surfactant based on solubility of drug, dissolution procedure is different for individual product. ${ }^{7}$ Whereas, bio relevant dissolution media is based on human gastro-intestinal condition and transit time. Dissolution volume and agitation speed are required to be modulated based on in vivo performance product. ${ }^{8}$

Various research works has been performed on formulation development and analytical method development. ${ }^{9-11}$ No research work has been performed on biorelevant dissolution method development of tamsulosin and dutasteride modified-release formulation. USP Apparatus 3 (reciprocating cylinder) is recommended for modifiedrelease dosage of multiparticulate drug delivery system, ${ }^{12}$ and it is having the scope to run with multiple dissolution media, by varying the speed. The biorelevant dissolution media for post-prandial condition, simulates the gastro-intestinal $\mathrm{pH}$ conditions of stomach, duodenum, jejunum, ileum, distal ileum and colon, with certain enzymes and residence time at each $\mathrm{pH}$ condition. ${ }^{13}$ Method development is performed using quality 
by design approach with risk assessment and statistical interpretation of data using appropriate software for multiple factors, instead of evaluating one factor at a time. ${ }^{14}$

A bio relevant dissolution method, by simulating human gastro-intestinal condition is aimed to develop in this research work, by optimising the factors influencing drug release profile. The correlation between percentage of drug absorbed through in vivo study and percentage of drug released through in vitro dissolution is established by in vitro/in vivo Correlation (IVIVC).

\section{MATERIALS AND METHODS}

Combodart $^{(\mathrm{R})}$ is procured from pharmacy. Dutasteride and tamsulosin hydrochloride is obtained as gift sample from Dr. Reddy's Laboratories, Hyderabad. Standard inorganic salts and solvents are procured from Merck. Pepsin 3000NF (Meteoric bio pharmaceuticals pvt. ltd), Lecithin (Soya lecithin India), Glyceryl monooleate (Danisco Specialities), Maleic acid (Sigma-Aldrich), Sodium oleate (Riedel-de Haën), Sodium taurocholate (Prodotti Chimici), Tetrahydro furan (Merck), Pancreatin powder (Scientific Protein Laboratories LLC) are procured from indigenous vendors and used for evaluation. Polyvinyl difluoride filters (0.45micron) are purchased from Rankem, India.

\section{Instrumentation}

Dissolution USP Apparatus 1 (Electrolab) and dissolution USP Apparatus 3 (Vankel 25-1000 BIO-DIS Reciprocating cylinder). Agilent 1200 RP-HPLC system consisting of a pump, an injector, UV detector, with an auto sampler and column heater, enabled with Empower software. Analytical Balance, Ultrasonic Bath, Centrifuge, $\mathrm{pH}$ meter, Oven and Mechanical shaker. Rotavap (type R-114, Buechi, Essen, Germany).

\section{METHODS}

\section{Deconvolution of Plasma profile}

The plasma drug concentration time profile obtained at post-prandial state is deconvoluted using Wagner-Nelson deconvolution method, to determine the fraction of drug absorbed.

\section{Quality control testing}

The quality control dissolution test is performed based on the recommendation from office of generic drugs. The dissolution of dutasteride and tamsulosin hydrochloride modified release capsules is performed in $0.1 \mathrm{~N} \mathrm{HCL}$ with $0.2 \%$ SLS for $2 \mathrm{hrs}$, followed by $\mathrm{pH} 7.2$ phosphate buffer for $8 \mathrm{hrs}$ by using USP Apparatus 1 and media volume of $900 \mathrm{ml}$. Chromatographic separation was achieved with Agilent's high performance liquid chromatography and bridge $C_{18}, 5 \mu \mathrm{m}, 4.6 \times 150 \mathrm{~mm}$ column, with the mobile phase- 1 of $0.05 \mathrm{M}$ phosphate buffer ( $\mathrm{pH} 6.3$ ) and mobile phase- 2 of acetonitrile by gradient elution technique. The flow rate is maintained at $1.5 \mathrm{ml} / \mathrm{min}$ and the detection wavelength is $225 \mathrm{~nm}$, with sample run time of 18 minutes.

\section{Biorelevant testing}

Biorelevant dissolution method is developed by quality by design approach. Tamsulosin being a modified-release pellet, Fed state simulated change over dissolution media are used with the aid of dissolution USP Apparatus 3. Dutasteride being an immediate-release part, dissolution method is developed without change over dissolution condition, by extending the run time, with the aid of dissolution USP Apparatus 3. Initial risk assessment is performed for factors, based on the risk priority number, the factors evaluated are DPM at 4 levels and media volume at 2 levels for tamsulosin. DPM, media volume and media are the factors evaluated at 2 levels for dutasteride.

A full factorial design of experiment is carried out using minitab software, study outcome is interpreted statistically. Biorelevant dissolution method is finalized based on desirability factor with percentage of drug absorbed. Level-A in vitro/in vivo correlation is established.

\section{RESULTS}

Deconvolution of plasma profile: The fraction of drug absorbed from Combodart at post-prandial state ${ }^{15}$ for tamsulosin and dutasteride are presented in Table 1. Under post-prandial condition 90\% tamsulosin absorbed in $12 \mathrm{hrs}$ and $93 \%$ dutasteride absorbed in $5 \mathrm{hrs}$, which directs the simulated dissolution method development is recommended to have $12 \mathrm{hr}$ for tamsulosin and $5 \mathrm{hr}$ for dutasteride.

Table 1: Fraction of drug absorbed from Combodart at post-prandial condition.

\begin{tabular}{|c|c|c|c|c|c|c|}
\hline \multirow[b]{2}{*}{$\begin{array}{c}\text { Time } \\
(\mathrm{hr})\end{array}$} & \multicolumn{3}{|c|}{ Tamsulosin $(\mathrm{N}=45)$} & \multicolumn{3}{|c|}{ Dutasteride $(\mathrm{N}=45)$} \\
\hline & $\begin{array}{c}\text { Mean drug plasma } \\
\text { concentration }(\mathrm{ng} / \mathrm{mL})\end{array}$ & $\begin{array}{l}\text { Fraction Abs. } \\
\text { (Numerical } \\
\text { Deconvolution) }\end{array}$ & $\begin{array}{c}\text { \%Absorbed } \\
\text { (Target profile) }\end{array}$ & $\begin{array}{l}\text { Mean drug plasma } \\
\text { concentration } \mathrm{Cp} \text { (ng/ } \\
\mathrm{mL} \text { ) }\end{array}$ & $\begin{array}{l}\text { Fraction Abs. } \\
\text { (Numerical } \\
\text { Deconvolution) }\end{array}$ & $\begin{array}{c}\text { \%Absorbed } \\
\text { (Target profile) }\end{array}$ \\
\hline 0.5 & - & - & - & 0.0 & 0.0 & 1.4 \\
\hline 1.0 & 0.2 & 0.0 & 1.6 & 0.1 & 0.0 & 2.6 \\
\hline 1.5 & - & - & - & 0.3 & 0.1 & 11.1 \\
\hline 2.5 & 1.6 & 0.1 & 11.9 & 0.8 & 0.4 & 37.2 \\
\hline 3.0 & 2.6 & 0.2 & 20.1 & 1.1 & 0.5 & 51.5 \\
\hline 4.0 & 4.8 & 0.4 & 37.4 & 1.4 & 0.7 & 70.4 \\
\hline 5.0 & 7.6 & 0.6 & 60.1 & 1.7 & 0.9 & 93.3 \\
\hline 24.0 & 3.3 & 0.95 & 95.3 & & & \\
\hline 48.0 & 0.9 & 0.97 & 97.4 & & & \\
\hline
\end{tabular}


Quality control dissolution testing: Dissolution profile of Combodart is performed using OGD recommended dissolution media. The dissolution of dutasteride is observed more than $90 \%$ in $1 \mathrm{hr}$ and the percentage absorbed is only $2.6 \%$ at $1 \mathrm{hr}$. Similarly, tamsulosin is observed with faster dissolution profile in comparison to percentage drug absorbed. The results are presented in Table 2 .

Biorelevant testing: Biorelevant dissolution method is developed by using quality by design (QBD) approach. Initial risk assessment is performed on variables such as residence time, $\mathrm{pH}$ of buffer, dissolution media, agitation speed and media volume. Risk assessment is measured in 3 categories, low (1), medium (2) and high (3). The risk number is the multiplication of all the three. The risk number more than 9 is considered for DOE study. Dissolution apparatus, dissolution media, media volume and DPM are considered as factors for dissolution evaluation. Based on the risk priority number (RPN) achieved, media volume and DPM are the two factors studied for tamsulosin. Media volume, dissolution media and DPM are the three factors studied for dutasteride. A full factorial design of experiment is established by using minitab software.

\section{Table 2: Comparative dissolution profile of Combodart in $0.1 \mathrm{~N} \mathrm{HCI}$ with $0.2 \%$ SLS for $2 \mathrm{hr}$, pH 7.2 phosphate buffer for $8 \mathrm{hr}$. USP Apparatus $1,900 \mathrm{ml}$, with target release profile.}

\begin{tabular}{ccccc} 
& \multicolumn{4}{c}{ Combodart 10367998A } \\
\cline { 2 - 5 } Time & \multicolumn{2}{c}{ Dutasteride } & \multicolumn{2}{c}{ Tamsulosin } \\
\cline { 2 - 5 } (hrs) & $\begin{array}{c}\text { Cumulative } \\
\text { \% drug } \\
\text { release }\end{array}$ & $\begin{array}{c}\text { Target release } \\
\text { (deconvoluted) }\end{array}$ & $\begin{array}{c}\text { Cumulative } \\
\% \text { drug } \\
\text { release }\end{array}$ & $\begin{array}{c}\text { Target release } \\
\text { (deconvoluted) }\end{array}$ \\
\hline 0 & 0 & 0 & 0 & 0 \\
0.5 & $70.8 \pm 0.6$ & 1.4 & $5.9 \pm 0.4$ & - \\
1 & $92.7 \pm 0.5$ & 2.6 & $11.7 \pm 0.6$ & 1.6 \\
1.5 & $98.5 \pm 0.4$ & 11.1 & $13.1 \pm 0.2$ & - \\
2 & $100.2 \pm 0.1$ & 22.7 & $15.9 \pm 0.3$ & 6.8 \\
3 & - & - & $46.7 \pm 0.5$ & 20.1 \\
4 & - & - & $75.5 \pm 0.7$ & 37.4 \\
6 & - & - & $98.6 \pm 0.3$ & 75.5 \\
8 & - & - & $99.6 \pm 0.1$ & 88.2 \\
$\mathrm{~F}_{2}$ & 7 & & 30 & \\
\hline
\end{tabular}

Note: mean \pm SD, $\mathrm{n}=3$
Dissolution media used for bio relevant dissolution method development are, Fed state simulated gastric fluid (FeSSGF), Fed state simulated intestinal fluid (FeSSIF) pH 5.8, pH 6.5 and pH 7.5, Simulated colonic fluid $(\mathrm{SCoF}) \mathrm{pH}$ 5.8. The composition and preparation of bio relevant dissolution media is followed as per literature.

A full factorial design of experiment study with factors and responses for biorelevant dissolution method is presented for tamsulosin in Table 3 and for dutasteride in Table 4. The dissolution media selected for evaluation of tamsulosin is Fed state simulated change over dissolution media (pH 5.0 FeSSGF for 2hr, pH 5.8 FeSSIF for 1hr, pH 6.5 FeSSIF for $1 \mathrm{hr}, \mathrm{pH} 7.5 \mathrm{FeSSIF}$ for $2 \mathrm{hrs}$ and $\mathrm{pH} 5.8 \mathrm{SCoF}$ for $6 \mathrm{hr}$ ). The dissolution media selected for dutasteride is $\mathrm{pH} 5.0$ Fed state simulated gastric fluid and $\mathrm{pH} 6.5$ Fed state simulated intestinal fluid.

Each dissolution study is performed using 3 units of Combodart, with the combination of different factors. The standard deviation below $2 \%$ confirms no significant variation within units. Dissolution data is further evaluated for statistical interpretation using minitab software for main effect, interaction effect of DPM and media volume on dissolution. Increase in DPM and media volume shows increase in drug release,

Table 3: Full factorial study design and responses on dissolution of tamsulosin from Combodart capsules under fed change over dissolution condition.

\begin{tabular}{cccccc}
\hline \multirow{2}{*}{$\begin{array}{c}\text { Run } \\
\text { Order }\end{array}$} & \multicolumn{2}{c}{ Factors } & \multicolumn{4}{c}{ Responses } \\
\cline { 2 - 6 } & DPM & Volume & $\begin{array}{c}\text { Dissolution } \\
4 \mathrm{hr}\end{array}$ & $\begin{array}{c}\text { Dissolution } \\
6 \mathrm{hr}\end{array}$ & $\begin{array}{c}\text { Dissolution } \\
12 \mathrm{hr}\end{array}$ \\
\hline Target & - & - & 37.4 & 75.5 & 90.0 \\
\hline 1 & 7 & 100 & $15.8 \pm 0.6$ & $36.3 \pm 0.5$ & $64.3 \pm 1.1$ \\
2 & 10 & 100 & $24.0 \pm 0.5$ & $41.7 \pm 0.4$ & $72.7 \pm 0.5$ \\
3 & 15 & 100 & $30.4 \pm 0.4$ & $53.2 \pm 0.6$ & $75.0 \pm 0.3$ \\
4 & 20 & 100 & $34.0 \pm 0.4$ & $62.0 \pm 0.7$ & $72.5 \pm 0.2$ \\
5 & 7 & 250 & $28.0 \pm 0.5$ & $63.1 \pm 0.6$ & $81.5 \pm 1.2$ \\
6 & 10 & 250 & $31.7 \pm 0.7$ & $65.2 \pm 0.4$ & $83.4 \pm 0.9$ \\
7 & 15 & 250 & $34.1 \pm 0.5$ & $69.0 \pm 0.6$ & $88.8 \pm 0.6$ \\
8 & 20 & 250 & $38.2 \pm 0.3$ & $76.3 \pm 0.5$ & $90.7 \pm 0.5$ \\
\hline
\end{tabular}

Note: mean $\pm \mathrm{SD}, n=3$

Table 4: Full factorial study design and responses on dissolution of dutasteride from Combodart capsules.

\begin{tabular}{ccccccc}
\hline \multirow{2}{*}{ Run Order } & \multicolumn{2}{c}{ Factors } & \multicolumn{5}{c}{ Responses } \\
\cline { 2 - 6 } & DPM & Volume & Dissolution media & Dissolution 1hrs & Dissolution 3hrs & Dissolution 5hrs \\
\hline Target & & & & $\mathbf{2 . 6}$ & $\mathbf{5 1 . 1}$ & $\mathbf{9 3 . 3}$ \\
1 & 7 & 100 & pH 5.0FeSSGF & $5.2 \pm 0.4$ & $51.1 \pm 1.1$ & $93.5 \pm 0.9$ \\
2 & 20 & 100 & pH 5.0FeSSGF & $9.9 \pm 0.4$ & $62.7 \pm 0.5$ & $97.3 \pm 1.1$ \\
3 & 7 & 250 & pH 5.0FeSSGF & $16.5 \pm 0.9$ & $66.0 \pm 0.8$ & $98.1 \pm 0.7$ \\
4 & 20 & 250 & pH 5.0FeSSGF & $22.9 \pm 0.5$ & $73.6 \pm 1.6$ & $98.5 \pm 0.1$ \\
5 & 7 & 100 & pH 6.5 FeSSIF & $8.8 \pm 0.4$ & $61.2 \pm 0.7$ & $93.1 \pm 0.4$ \\
6 & 20 & 100 & pH 6.5 FeSSIF & $12.2 \pm 0.3$ & $64.5 \pm 0.9$ & $94.8 \pm 0.5$ \\
7 & 7 & 250 & pH 6.5 FeSSIF & $18.8 \pm 0.4$ & $68.8 \pm 0.5$ & $99.0 \pm 0.7$ \\
8 & 20 & 250 & pH 6.5 FeSSIF & $25.7 \pm 1.0$ & $75.4 \pm 0.7$ & $99.2 \pm 0.3$ \\
\hline
\end{tabular}

Note: mean $\pm \mathrm{SD}, n=3$ 
the response is presented in Figure 1, desirability factor is derived from response optimization, presented in Figure 2 for tamsulosin. ANOVA results of DOE study and model summary are presented in Table 5 for tamsulosin. The $\mathrm{p}$ value observed was less than 0.05 , which confirms the model is significant.

For dutasteride, the design of experiment study performed through various dissolution run for evaluating the impact of dissolution media, DPM and media volume. Statistical interpretation of data on main effect, interaction effect of dissolution media, DPM and media volume on dissolution are presented in Figure 3, desirability factor is derived by response optimization plot, presented in Figure 4 for dutasteride.
ANOVA results of DOE study and model summary are presented in Table 5 for dutasteride.

Dissolution profile is compared using optimised method for tamsulosin and percentage drug absorbed, the results are presented in Table 6 and Figure 5.

Percentage of drug absorbed obtained from deconvoluted in vivo data tamsulosin is compared with percentage of drug dissolved under simulated fed condition.The fraction of drug absorbed in vivo is consistently comparable to the fraction of drug released in vitro indicating over-discriminating dissolution conditions. The slope observed by

Table 5: ANOVA results for Design of experiment - Combodart.

\begin{tabular}{|c|c|c|c|c|c|c|c|c|}
\hline \multirow{3}{*}{ Source } & \multirow{3}{*}{$\begin{array}{l}\text { Degrees of } \\
\text { freedom }\end{array}$} & \multicolumn{3}{|c|}{ Dutasteride dissolution at } & \multirow{3}{*}{$\begin{array}{l}\text { Degrees of } \\
\text { freedom }\end{array}$} & \multicolumn{3}{|c|}{ Tamsulosin dissolution at } \\
\hline & & $1 \mathrm{hr}$ & $3 \mathrm{hrs}$ & $5 \mathrm{hrs}$ & & 4hrs & $6 \mathrm{hrs}$ & $12 \mathrm{hrs}$ \\
\hline & & \multicolumn{3}{|c|}{ Adjusted sum square } & & \multicolumn{3}{|c|}{ Adjusted sum square } \\
\hline Linear & 3 & 358.0 & 385.2 & 37.3 & 4 & 319.8 & 1254.1 & 553.9 \\
\hline DPM & 1 & 57.2 & 105.9 & 4.7 & 3 & 223.2 & 446.1 & 105.4 \\
\hline Media & 1 & 15.1 & 34.0 & 0.2 & - & - & - & - \\
\hline 2-Way Interactions & 3 & 3.5 & 17.5 & 6.2 & 3 & 23.1 & 54.3 & 17.5 \\
\hline $\mathrm{DPM}^{\star}$ Media Volume & 1 & 3.4 & 0.1 & 3.0 & 3 & 23.1 & 54.3 & 17.5 \\
\hline $\mathrm{DPM}^{*}$ Media & 1 & 0.1 & 10.8 & 0.7 & - & - & - & - \\
\hline Media Volume ${ }^{\star}$ Media & 1 & 0.1 & 6.7 & 2.5 & - & - & - & - \\
\hline Variance Inflation Factor & - & 1.50 & 1.50 & 1.50 & - & 1.0 & 1.0 & 1.0 \\
\hline
\end{tabular}
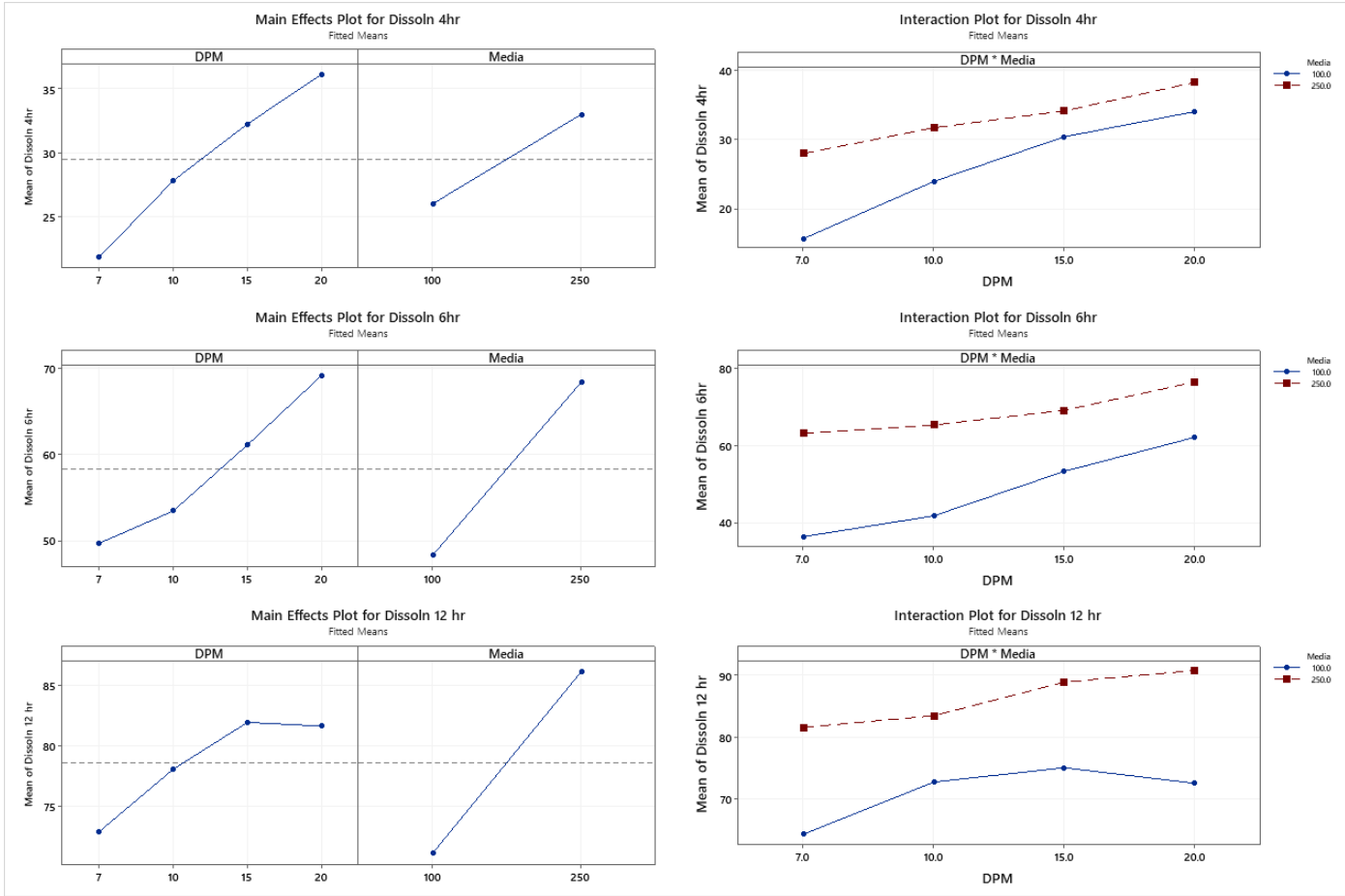

Figure 1: Main effect and interaction effect on DPM and media volume on dissolution profile of tamsulosin under postprandial condition. 


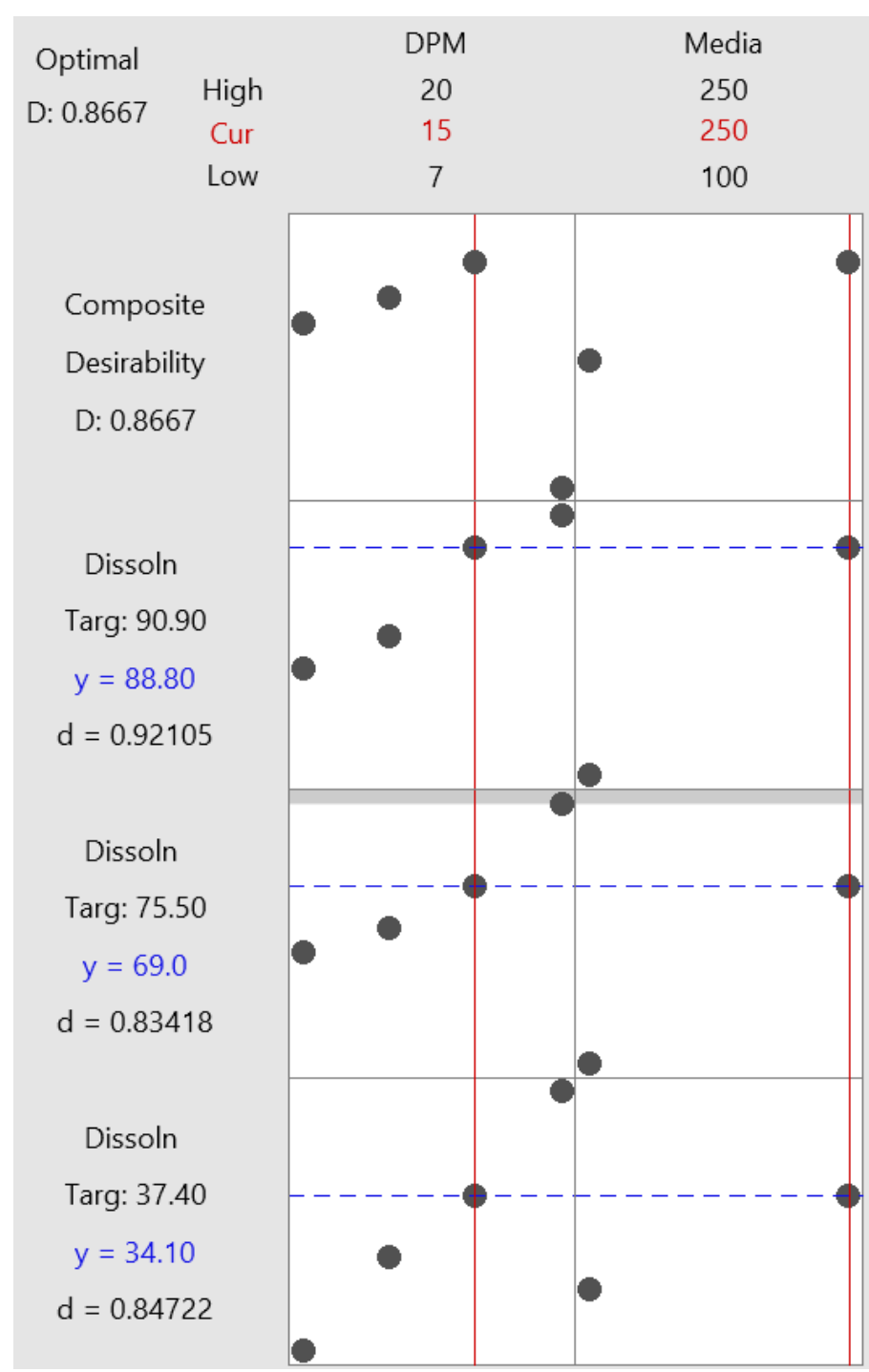

Figure 2: Response optimisation for dissolution of tamsulosin from Combodart under post-prandial condition at $4 \mathrm{hr}, 6 \mathrm{hr}$ and $12 \mathrm{hr}$.
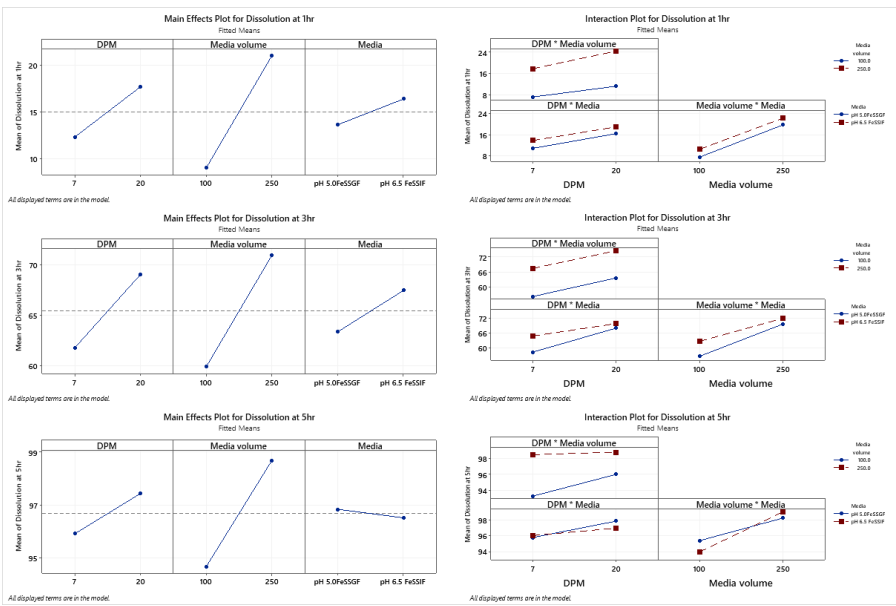

Figure 3: Main effect and interaction effect on DPM, media and media volume on dissolution profile of dutasteride under post-prandial condition.

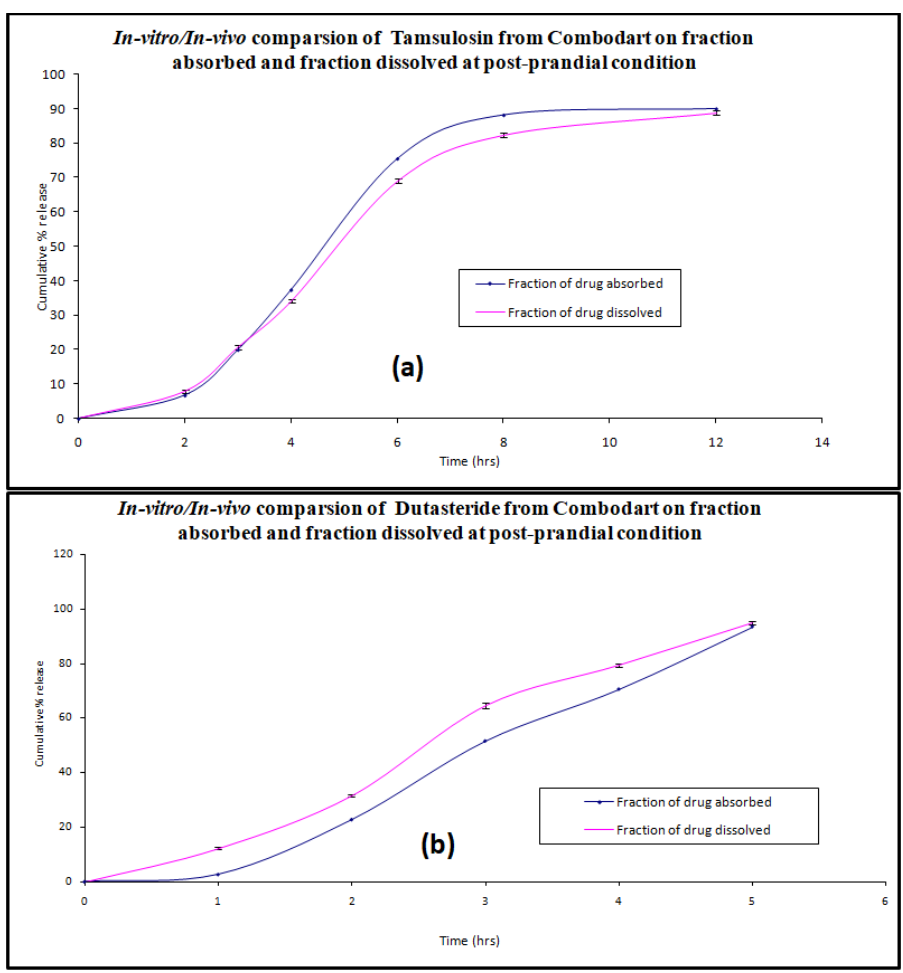

Figure 5: In vitro/in vivo comparison of Combodart - on fraction of drug absorbed by in vitro and fraction of drug dissolved by in vitro- a) Tamsulosin b) Dutasteride. The $y$-axis represents $\%$ drug release and the $x$-axis denotes times in hours. Data represent mean \pm standard deviation, $n=3$.

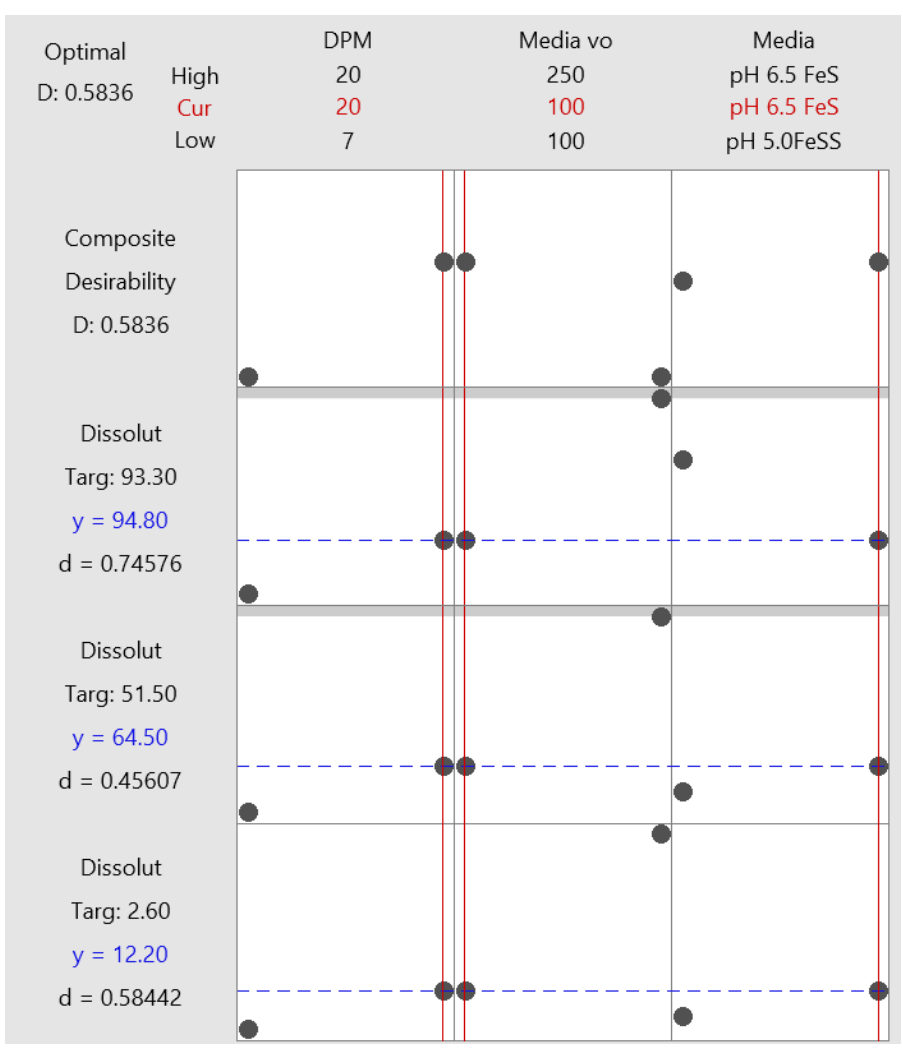

Figure 4: Response optimisation for dissolution of dutasteride from Combodart under post-prandial condition at $1 \mathrm{hr}, 3 \mathrm{hr}$ and $5 \mathrm{hr}$. 
Table 6: In-vitro/In-vivo comparison of dutasteride and tamsulosin from Combodart on fraction absorbed and fraction dissolved at postprandial condition.

\begin{tabular}{cccc}
\hline Dissolution (time) & $\begin{array}{c}\text { Cumulative } \\
\text { Time (hrs) }\end{array}$ & $\begin{array}{c}\text { Cumulative } \\
\% \text { drug } \\
\text { release }\end{array}$ & $\begin{array}{c}\text { Target } \\
\text { profile } \\
(\% \\
\text { absorbed) }\end{array}$ \\
\hline \multicolumn{4}{c}{ Tamsulosin Part } \\
FeSSGF pH 5.0 for 120 mins & 2 hrs & $7.9 \pm 0.4$ & 6.8 \\
pH 5.8 New- FeSSIF for 60 mins & 3 hrs & $20.7 \pm 0.5$ & 20 \\
pH 6.5 Half-FeSSIF for 60 mins & 4 hrs & $34.1 \pm 0.5$ & 37.4 \\
pH 7.5 FeSSIF- sans for 120 mins & 6 hrs & $69.0 \pm 0.6$ & 75.5 \\
pH 5.8 SCoF for 120 mins & 8 hrs & $82.4 \pm 0.6$ & 88.2 \\
pH 5.8 SCoF for 240 mins & 12 hrs & $88.8 \pm 0.6$ & 90.9 \\
F2 & & 70 & \\
& Dutasteride Part & & \\
pH 6.5 FeSSIF for 1 hour & 1 hour & $12.2 \pm 0.3$ & 2.6 \\
pH 6.5 FeSSIF for 2 hours & 2 hours & $31.6 \pm 0.5$ & 22.7 \\
pH 6.5 FeSSIF for 3 hours & 3 hours & $64.5 \pm 0.9$ & 51.5 \\
pH 6.5 FeSSIF for 4 hours & 4 hours & $79.3 \pm 0.7$ & 70.4 \\
pH 6.5 FeSSIF for 5 hours & 5 hours & $94.8 \pm 0.5$ & 93.3 \\
F2 & & 52 & \\
\hline
\end{tabular}

Note: mean $\pm S D, n=3$

correlating in vitro/in vitro is $\mathrm{y}=0.913 \mathrm{x}+0.991$. The regression coefficient $\left(R^{2}\right)$ value of 0.998 also indicates very good predictive capability of the relationship.

Dissolution profile is compared using optimised method for dutasteride and percentage drug absorbed, the results are presented in Table 6 and Figure 5.

Percentage of drug absorbed obtained from deconvoluted in vivo data for dutasteride is compared with percentage of drug dissolved under simulated fed condition. The fraction of drug released in vitro is consistently comparable to the fraction of drug released in vitro indicating over discriminating dissolution conditions. The slope observed from in vitro/in vitro correlation is $\mathrm{y}=0.997 \mathrm{x}+7.072$. The regression co-efficient $\left(R^{2}\right)$ value of 0.982 also indicates very good predictive capability of the relationship.

\section{DISCUSSION}

Biorelevant dissolution methods are the predictive tool for in vivo performance of drug product. The percentage of drug absorbed is determined by deconvolution of plasma profile shows the difference in release profile, more than $85 \%$ of drug is absorbed for tamsulosin at $8 \mathrm{hrs}$ and dutasteride at $5 \mathrm{hrs}^{15}$, which recommends developing biorelevant dissolution method for certain dissolution run duration. Combodart is evaluated for dissolution using quality control method resulted in faster dissolution profile in comparison to percentage of drug absorbed, with the $\mathrm{F}_{2}$ value 7 for dutasteride and 30 for tamsulosin.

Hence, a bio-predictive dissolution method to characterize the in vivo performance of drug product is developed. This dissolution method involves incorporation of multiple dissolution medium and preparation of dissolution medium used to simulate the gastrointestinal condition. ${ }^{8}$ Tamsulosin being modified-release dosage form, change over dissolution media simulating post-prandial condition is used for dissolution evaluation up to $12 \mathrm{hr}$. Dutasteride being an immediate-release dosage form, single dissolution media is used by extending the dissolution run time upto 5hrs. A separate biorelevant dissolution method is developed, based on the formulation design and release profile of dutasteride and tamsulosin. A quality by design approach is adopted. The initial risk assessment performed on factors affecting dissolution performance directs, DPM and media volume are the significant factors to be studied for tamsulosin. DPM, media volume and media are the significant factors to be studied for dutasteride. A full factorial design of experiment study was performed. ${ }^{14}$

For tamsulosin, increase in agitation speed and media volume is having increase in dissolution. From the ANOVA results, $p$ value less than $0.05 \%$ and the total sum of square attributed only to the factors without residual error concludes the model is significant, with the model summary of $100 \%$. Interaction effect is not having significant contribution in model. The dissolution response at $4 \mathrm{hrs}, 6 \mathrm{hr}$ and $12 \mathrm{hr}$ are evaluated by varying the factors and multiple responses is plotted using minitab software, indicates the predictive biorelevant dissolution method for tamsulosin from Combodart is USP Apparatus 3, 15DPM and 250ml of change over dissolution media, with the composite desirability of 0.8767 . The composite desirability is not based on closeness of dissolution with percentage drug absorbed, it includes other variable factors studied throughout the experiment. The dissolution profile of optimized biorelevant dissolution method, with inclusion of multiple dissolution time points compared with fraction of drug absorbed, resulted $\mathrm{F}_{2}$ value of 70 and complies to level a in vitro/in-vivo correlation, with regression co-efficient value of 0.998 . USP apparatus 3 is programmable to run dissolution in different media and at different speed at various time

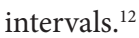

For dutasteride, increase in agitation speed and media volume is having increase in dissolution. Change in dissolution media is not having significant impact on dissolution. The interpretation of interaction between DPM and media volume are not having significant impact on dissolution, whereas the interaction effect dissolution media and volume are having significant impact on dissolution. The dissolution response at $1 \mathrm{hr}, 3 \mathrm{hr}$ and $5 \mathrm{hr}$ evaluated by varying the factors and multiple response was plotted using minitab software, indicates the predicted biorelevant dissolution method for dutasteride from Combodart is USP Apparatus 3, 20DPM and $100 \mathrm{ml}$ of $\mathrm{pH} 6.5$ Fed state simulated intestinal fluid dissolution media, with the composite desirability of 0.5836 . The dissolution profile of optimized biorelevant dissolution method, with inclusion of multiple dissolution time points compared with fraction of drug absorbed, resulted the $\mathrm{F}_{2}$ value of 52 and complies to level a in vitro/ in vitro correlation, with regression co-efficient value of 0.982 .

The conventional approach is to recommend the dissolution profile closest to target profile. Whereas, QBD approach recommends the desirable dissolution profile, by considering multiple factors, main effect and interaction effect. Biorelevant dissolution methods shall be used when there is change in batch size, process change, API change, excipient change or equipment change. The developed dissolution method shall be used as a predictive tool for in vivo absorption and potential tool for the establishment of IVIVC.

\section{CONCLUSION}

Biorelevant dissolution method developed using USP Apparatus 3, coupled with a deconvolution approach is found to be successfully correlating the in vivo performance of tamsulosin and dutasteride modified-release capsules after oral administration under the fed state.

\section{ACKNOWLEDGEMENT}

Authors are thankful to Malla Reddy Pharmacy College, Hyderabad and Dr. Reddy's Laboratories for providing all necessary facilities for conducting the study. 


\section{CONFLICT OF INTEREST}

The authors declare no conflict of interest.

\section{ABBREVIATIONS}

USP: United States of Pharmacopeia; OGD: Office of Generic Drugs; DPM: Dips per minute; NF: National Formulary; RP-HPLC: Reverse phase High performance liquid chromatography; $\mathbf{H C l}$ : Hydrochloric acid; SLS: Sodium lauryl sulphate; USFDA: United States Food and Drugs Administration; DOE: Design of Experiment; RPN: Risk priority number; SD: Standard deviation; ANOVA: Analysis of variance.

\section{REFERENCES}

1. Miller J, TarterTH. Combination therapy with dutasteride and tamsulosin for the treatment of symptomatic enlarged prostate.Clinic Interv Aging. 2009;4:251-8.

2. US Food and Drug Administration, Silver Spring, MD 20993, Centerfor Drug Evaluation and Research, Printed Labelling for Jalyn (Dutasteride $0.5 \mathrm{mg}$ tamsulosin hydrochloride $0.4 \mathrm{mg}$ ). 2010. Available from: https://www.accessdata.fda.gov/drugsatfda_docs/nda /2010/0224600rig1s000LBL.pdf.

3. Sajid Ali, Sarfaraz A, Nawazish A, Masoom R. Preparation, Characterization and stability study of dutasteride loaded nanoemulsion for treatment of benign prostatic hypertrophy. Iran J Pharm Res. 2014;13(4):1125-40.

4. Khawla R. Wagner-Nelson and numerical deconvolution based approaches for in vitro performance prediction. Int J Sci Res. 2018;7(8):1646-9.

5. Martin S, Jennifer D, Cynthia B, Vinod S. AAPS guidelines for dissolution/ in vitro release testing of novel/special dosage forms. AAPS Pharm Sci Tech. 2003;4(1):6-15.
6. Ramesh B. Method development and validation for dissolution testings. Res J Pharm Biol Chem Sci. 2011;2(1):561-74.

7. Zaborenko N, Zhenqi S, Claudia C, Brandye M, Smith G, Limin Z, et al. Firstprinciples and empirical approaches to predicting in vitro dissolution for pharmaceutical formulation and process development and for product release testing. The AAPS Journal. 2019;21(3):32.

8. Sandra K. The use of biorelevant dissolution media to forecast the in vitro performance of a drug. The AAPS Journal. 2010;12(3):397-406.

9. Raja S, Christopher VJ. Analytical method development and validation of dutasteride and tamsulosinhcl in combination and its stress degradation studies. Inter JPharm Anal Research. 2013;2(2):74-83.

10. Mrudula D, Saiprasad G, Rao PV. Simultaneous estimation and validation of tamsulosin and deutasteride in bulk and pharmaceutical dosage form. International Journal of Research in Pharmaceutical and Nano Sciences. 2014;3(4):2428.

11. Shivakumar R, Prasad R. Development and validation of a stability indicating liquid chromatographic method for simultaneous estimation of dutasteride and tamsulosin in combined dosage form. Orient J Chem. 2013;29(4):1665-73.

12. Chiluba M, Sandile M, Khamanga M, Roderick B. Development and assessment of a USP apparatus 3 dissolution test method for sustained-release nevirapine matrix tablets. Dissolut Technol. 2016:8:22-30.

13. Jantratid E, Maio D, Ronda E, Mattavelli V, Vertzoni M, Dressman J. Application of biorelevant dissolution tests to the prediction of in vitro performance of diclofenac sodium from an oral modified-release pellet dosage form. Eur J Pharm Sci. 2009;37(3-4):434-41.

14. Ramalingam $P$, Kalva B. Analytical Quality by Design: A tool for regulatory flexibility and robust analytics. IntJ Anal Chem. 2015;(1):1-9.

15. Valery A, Fernando C, Maria F, Gilberto B, Ana C. Bioequivalence between two fixed dose combinations of dutasteride and tamsulosin in male subjects under fasting and fed conditions. Int Ann Med. 2017;1(10):1-7.

Article History: Submission Date : 20-05-2020; Revised Date : 07-07-2020; Acceptance Date : 24-09-2020.

Cite this article: Thamizhanban D. Biorelevant Dissolution Method Development for Dutasteride and Tamsulosin Hydrochloride Modified Release Capsule Simulating Post-prandial Condition. Int. J. Pharm. Investigation, 2020;10(3):357-63 